IZA DP No. 8310

Using Cognitive Dissonance to Manipulate Social Preferences

Robert J. Oxoby

Alexander Smith

July 2014 


\title{
Using Cognitive Dissonance to Manipulate Social Preferences
}

\author{
Robert J. Oxoby \\ University of Calgary, \\ CIFAR and IZA
}

Alexander Smith

Worcester Polytechnic Institute

Discussion Paper No. 8310

July 2014

IZA
P.O. Box 7240
53072 Bonn
Germany

Phone: +49-228-3894-0

Fax: +49-228-3894-180

E-mail: iza@iza.org

Any opinions expressed here are those of the author(s) and not those of IZA. Research published in this series may include views on policy, but the institute itself takes no institutional policy positions. The IZA research network is committed to the IZA Guiding Principles of Research Integrity.

The Institute for the Study of Labor (IZA) in Bonn is a local and virtual international research center and a place of communication between science, politics and business. IZA is an independent nonprofit organization supported by Deutsche Post Foundation. The center is associated with the University of Bonn and offers a stimulating research environment through its international network, workshops and conferences, data service, project support, research visits and doctoral program. IZA engages in (i) original and internationally competitive research in all fields of labor economics, (ii) development of policy concepts, and (iii) dissemination of research results and concepts to the interested public.

IZA Discussion Papers often represent preliminary work and are circulated to encourage discussion. Citation of such a paper should account for its provisional character. A revised version may be available directly from the author. 
IZA Discussion Paper No. 8310

July 2014

\section{ABSTRACT}

\section{Using Cognitive Dissonance to Manipulate Social Preferences}

We explore the role of cognitive dissonance in dictator and public goods games. Specifically, we motivate cognitive dissonance between one's perception of "fair treatment" and selfinterested behaviour by having participants answer a question about fairness. Utilizing two manipulations (reminding participants about their answer to the fairness question and publicly reporting aggregate answers to the question), we find that there is greater cognitive dissonance and behavioural change when there is a social component (i.e., reporting of aggregate answers). When a participant's answer to the fairness question is private, there is less dissonance and hence no behavioural change.

JEL Classification: C91, D64, H41

Keywords: cognitive dissonance, experiments, social preferences

Corresponding author:

Robert J. Oxoby

Department of Economics

University of Calgary

2500 University Drive

Calgary $A B, T 2 N 1 N 4$

Canada

E-mail: oxoby@ucalgary.ca

\footnotetext{
* Financial support for this project was provided by the Social Sciences and Humanities Research Council (SSHRC) of Canada.
} 


\section{Introduction}

According to Festinger's (1957) theory of cognitive dissonance, people reduce mental dissonance between conflicting cognitions and behaviours by changing either their cognitions or their behaviours. Since Festinger (1957), the theory of cognitive dissonance has undergone many revisions, perhaps the most notable being that of Aronson (1992, 1994), who argued that cognitive dissonance is especially acute in situations where cognitions and behaviours reflect upon self-esteem or social-image. While the theory of cognitive dissonance has received substantial attention in psychology, its incorporation into economic models of decision-making has been limited. Akerlof and Dickens (1982) were the first to explicitly model cognitive dissonance as it pertains to affecting individuals' beliefs while Rabin (1994) used cognitive dissonance to model changes in social norms. This theory has also been utilized to explain the formation of behaviourally distinct social groups (Montgomery, 1994; Oxoby, 2003, 2004), and the formation of beliefs regarding one's own abilities and experience (Prendergast and Stole, 1996; Benabou and Tirole, 2011).

One key question in this literature however has been under what circumstances is cognitive dissonance strongest and thereby most successful in implementing behavioural change. Following the original formulation of Festinger (1957), any cognition (e.g., smoking has harmful health effects) could be dissonant with behaivour (e.g., smoking) and thereby create dissonance resulting in behavioural or cognitive change. That is, to reduce the dissonance between cognitions and behaviour, an individual will modify one or the other (e.g., quit smoking or discount the il health effects). However, more modern research on cognitive dissonance (notably Aronson, 1994 and Harmon-Mills and Jones, 1999) argues that dissonance is particularly acute (and therefore more effective in changing behaviour) when the conflict is between behaviour and cognitions that reflect on one's self-esteem or social-image. In the case of the smoking example, this implies that holding conflicting behaviours and beliefs (e.g., smoking and knowing the ill health effects) 
would not bring about as much dissonance as holding conflicting behaviours and beliefs that one must report publicly (e.g., smoking and publicly announcing the health effects of smoking).

In this paper, we present the results of two experiments in which we manipulate the degree of dissonance an individual may experience regarding cognitive support of "fair" treatment of individuals and self-interested behaviour in a dictator game and a public goods game. Specifically, we use recall (i.e., a private reminder of one's attitude towards fairness) and commitment (social reporting of aggregate attitudes towards fairness) as mechanisms to promote dissonance between (naive) self-interest and pro-social behaviour.

In our recall mechanism, participants are reminded about statements they have made regarding the importance of fairness. In our commitment mechanism, individuals' statements about fairness are socially displayed. Each of these provides a means of promoting cognitive dissonance by increasing potential tension between an individual's desire to maximize her personal returns in the experiment and behaving in a fair manner, in which fairness is construed as more equal payments to all participants. We find that commitment increases the prevalence of pro-social behaviour while recall does not. Since the commitment mechanism involves a social component and the recall mechanism is private, the results suggest that cognitive dissonance is more pronounced and more able to motivate behavioural change when the dissonance mechanism includes a social component.

Other researchers have experimentally studied the behavioral effects of cognitive dissonance. Konow (2000) demonstrates that perceptions of entitlement to assets (along with subsequent allocation decisions) are affected by dissonance. Related to this, Dickinson and Oxoby (2011) show that dissonance reduction can take the form of dispositional pessimism, which influences subsequent decision-making. More recently, Falk and Zimmermann (2011) have examined how preferences for consistency affect economic decision-making. In their third experiment, they examine whether asking participants how much they would give in a hypothetical situation can be used to manipulate real 
giving. Somewhat surprisingly, they find that asking about hypothetical giving biases real giving downward. Thus, compared to Falk and Zimmermann (2011), we show that cognitive dissonance can be used to promote pro-social behaviour. We also compare the effectiveness of different mechanisms.

Our experiments broadly follow the ideas laid out in Dickerson et al (1992). In those experiments, participants at a university swimming facility were asked to sign a petition or publicly visible poster regarding the need to conserve water. Both the poster and the petition emphasized using less water while showering by turning off the water while applying soap. The authors hypothesized that signing a publicly visible poster would engender a stronger sense of cognitive dissonance between the concept of self ("I behave in a way I would like others to behave"; here, in terms of conserving water) and behaviour (e.g., turning off the water in the shower while applying soap). The results of the experiment supported this hypothesis: participants signing the poster were significantly more likely to reduce their water use during showering than were those in the petition treatment.

In a similar experimental protocol, Mazar et al (2008) had participants commit to follow an honour code before they completed a math task and reported their results to the experimenters. participants asked (and agreeing) to follow the honour code were significantly more honest about their performance than those who were not asked to follow the code. As in Dickerson et al (1992), the authors hypothesized that it was creating a threat to the participants' sense of self that helped to promote the honest behaviour.

In our experiment, we apply the same logic as in Dickerson et al (1992) (exploiting the difference between private and public expressions of the need to treat people fairly) to explore the effects of cognitive dissonance manipulations in simple economic games. Our results contribute to the literature on how cognitive dissonance affects economic decisionmaking by showing that increasing dissonance using a social mechanism promotes prosocial behaviour. An important implication of the dictator game results is that cognitive dissonance is a useful mechanism for achieving equitable allocations of resources. In the 
public good game, we see that cognitive dissonance can be used for promoting cooperation, leading to increases in total surplus.

We are not the first to consider cognitive dissonance as a tool for policy implementation. James and Gutkind (1985) examine how dissonance reduction can be used for implementing development policies, arguing that policies implemented by internal organizations, such as local governments, can lead to changes in attitudes over time (e.g. family planning). Changes initiated by external organizations, like the World Bank, do not arouse the same dissonance and do not affect attitudes in the same way (e.g., on economic/political issues).

\section{Dictator Game}

Our first experiment sought to explore how cognitive dissonance could be used to manipulate social preferences in a simple allocation game. Specifically, we used a binary choice dictator game to identify how having participants agree to a statement regarding fairness could affect subsequent choices. Participants were asked to choose an allocation between themselves and a randomly assigned receiver $\left(x_{1}, x_{2}\right) \in\{(5,5),(8,2)\}$, where $x_{1}$ denotes the amount of money an individual allocated to herself (as the dictator) and $x_{2}$ denotes the amount allocated to the receiver. We used the strategy method wherein all participants made allocation decisions prior to knowing their roles in the dictator game. That is, individuals made the allocation decision $\left(x_{1}, x_{2}\right)$ prior to knowing whether they would be in the role of the dictator or receiver. After all decisions were made, participants were randomly paired, the role of dictator was randomly assigned within each pair, and the dictator's choice $\left(x_{1}, x_{2}\right)$ was implemented. Thus, for each participant, there was a $50 \%$ probability that her allocation decision would be implemented. ${ }^{1}$

\footnotetext{
${ }^{1}$ McLeish and Oxoby (2004) show that in ultimatum bargaining, the method yields results similar to standard methods where an individual knows her role in the game and thus, that her choice will be implemented. Brandts and Charness (2011) survey the literature on the strategy method and find that with few exceptions, the method gives similar results to the more conventional sequential method.
} 
Our experimental manipulations were implemented through an initial question asked of all participants prior to making allocation decisions. Specifically, all participants were asked whether they agreed or disagreed with the following:

Do you agree with the statement that all individuals at (our university) should be treated fairly by the administration, faculty, and other students?

The question was deliberately constructed to be vague with respect to the definition of fairness and the domains in which fairness was important. As such, participants could interpret the question in any number of ways. Given the vagueness of the question, we expected most participants to agree with the question. From this question, we implemented a $2 \times 2$ (treatment variables: recall and commitment) between-participants design.

In the baseline (no recall/no commitment) treatment, participants answered the question and proceeded to the second stage of the experiment in which they made decisions $\left(x_{1}, x_{2}\right)$ in the previously described dictator game.

In the recall treatment, participants were reminded of how they answered the fairness question when making their allocation decisions. That is, if a participant answered that she agreed/disagreed with the statement about fairness, the following message was presented at the time she made her decision in the dictator game:

You agreed/disagreed with the statement that all individuals at (our university) should be treated fairly be the administration, faculty, and other students.

In the commitment treatment, participants were informed that the responses to the fairness question would be aggregated and reported to all participants at the end of the experiment. In other words, participants were told that after making their allocation decisions, they would be informed of the percentages of participants who had agreed and disagreed with the fairness statement. This is similar in spirit to the experiments conducted by Dickerson, et al (1992) wherein they utilize signatures on a publicly posted 
petition regarding water conservation to encourage reductions in water usage among participants.

Finally, in the combined treatment, participants were reminded of their answers (as in the recall treatment) and told that the aggregate responses would be reported at the end of the experiment (as in the commitment treatment).

At the end of the experiment, participants were paid privately based on the implemented decisions in the dictator game.

The recall and commitment manipulations were designed to produce cognitions regarding the fair treatment of others. Within the context of the dictator game, this produces cognitive dissonance in which these cognitions are inconsistent with self-interested behaviour (i.e., choosing $\left.\left(x_{1}, x_{2}\right)=(8,2)\right)$. Consistent with the theory of cognitive dissonance (Festinger, 1957) and prior experiments (e.g., Dickerson et al, 1992), we hypothesize that these manipulations result in participants choosing the equal allocation $\left(x_{1}, x_{2}\right)=(5,5)$ as a means of reducing dissonance in the recall, commitment, and combined treatments.

Hypothesis 1 Participants in the recall, commitment, and combined treatments will display a greater likelihood of choosing the equal allocation in the dictator game relative to the baseline treatment.

\section{Results}

The experiment was conducted in our university's experimental economics laboratory and programmed using the software developed by Fischbacher (2007). Participants were recruited from the undergraduate student body and 160 individuals participated in the experiment. No participant participated in more than one treatment, nor did any participant participate in our second experiment (Section 3). Participants received $\$ 5$ show-up fees in addition to their payoffs from the dictator game. 
Answers to the fairness question were identical across treatments with all participants agreeing with the statement about fairness. There are, however, important differences in behaviour in the dictator game. Figure 1 shows the proportion of participants in each treatment who chose $\left(x_{1}, x_{2}\right)=(5,5)$, the dissonance reducing allocation. We find a noticeable increase in equal allocations when individuals are told that they will be provided with information regarding aggregate responses to the fairness question (our commitment treatment variable). It is interesting to note that this information is only provided after the participants make their allocation decisions, and as such does not affect the objective information they have (e.g., how many people agree with the fairness statement as a measure of the prevalence of fairness norms) at the time of choosing $\left(x_{1}, x_{2}\right)$. Interestingly, we find no effect of providing participants with a reminder of their answer to the question (comparing the recall and baseline treatments).

Figure 1: Proportions choosing equal payoffs

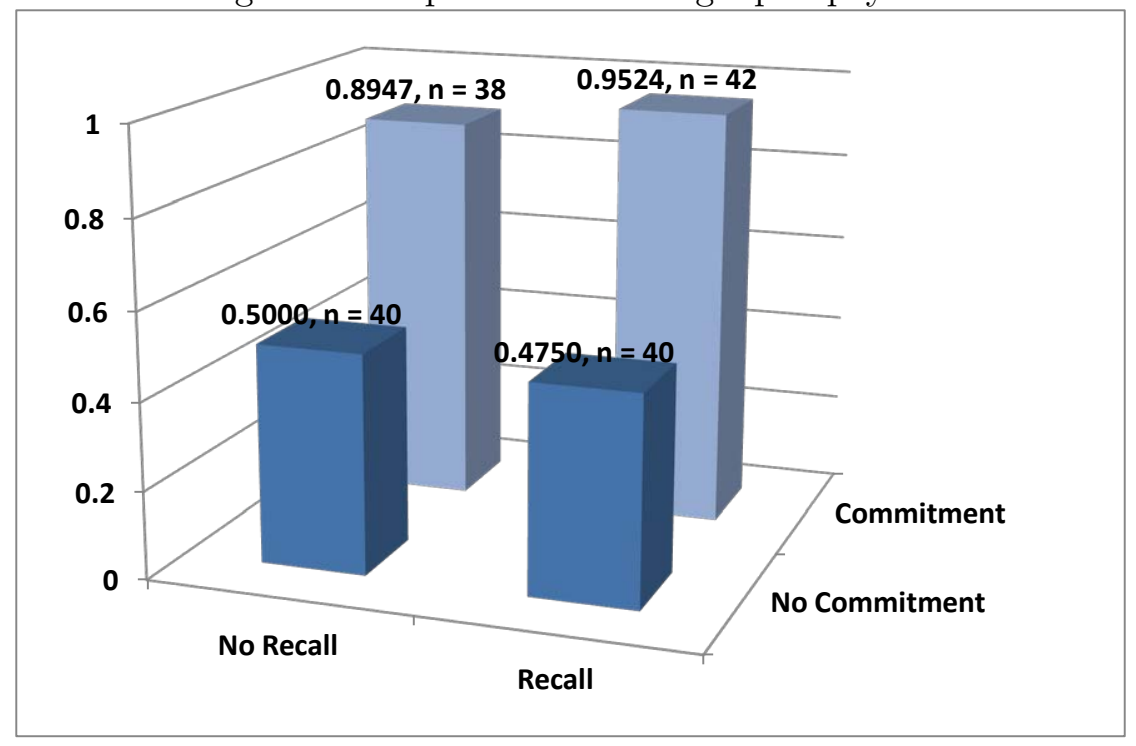

Table 1 presents the Wilcoxon $p$-values for pairwise comparisons between treatments. We can reject the null hypothesis that allocation decisions are drawn from the same distribution when comparing the commitment and combined treatments with the baseline and 
recall treatments. That is, of the statistically significant differences, all are attributable to the (potential) commitment treatment variable informing participants of aggregate responses to the fairness question. Specifically, with and without commitment, recall does not have a significant effect $(p=0.3314$ and $p=0.8241)$. In contrast, commitment has highly significant effects with and without recall $(p<0.01$ and $p<0.01)$, suggesting that commitment promotes pro-social behaviour, but recall does not. This is similar to the results reported in Dickerson et al (1992) in which individuals reduced their water use only when they were informed that their responses to a water conservation question would be made public.

Table 1: Wilcoxon $p$-values for comparisons between treatments

\begin{tabular}{lccc} 
& recall & commitment & combined \\
\hline baseline & 0.8241 & 0.0002 & 0.0000 \\
recall & - & 0.0001 & 0.0000 \\
commitment & - & - & 0.3314
\end{tabular}

\section{Public Good Game}

The results from our dictator game demonstrate that providing the potential for dissonant cognitions through the use of our commitment treatment variable can increase the frequency of allocation decisions that favour equality. However, in this environment there is very little uncertainty about the implications of decisions (i.e., with the exception of using the strategy method, a participant knows what her allocation decision implies for payoffs) and there are few individuals affected by the decision (i.e., there are only two participants in each dictator game pair). To expand our line of inquiry, we chose to use the same experimental protocol in the context of a linear public good game experiment in which participants chose among three contribution levels. Specifically, individuals were randomly assigned to groups of four participants and provided with an endowment of 10 lab dollars ( $\mathrm{LD}$; later converted to Canadian dollars at a rate of $1 \mathrm{LD}=\$ 0.50)$. Partic- 
ipants were restricted in making contribution decisions $c_{i} \in\{2,5,8\}$ to the public good with each participant $i$ 's payoff from the public good game determined by

$$
\pi_{i}=10-c_{i}+0.4 \sum_{j=1}^{4} c_{j}
$$

As in the dictator game experiment, we used a $2 \times 2$ (treatment variables: recall and commitment) between-participant design in which all participants were asked whether they agreed or disagreed with the aforementioned fairness question.

In the baseline (no recall/no commitment) treatment, participants answered the fairness question and then made their contribution decisions $c_{i}$ in the public good game. In the recall treatment, participants were reminded of their answer to the fairness question prior to making their contribution decisions, while in the commitment treatment, participants were informed that the aggregate responses to the fairness question would be reported after all contribution decisions had been made. In the combined treatment, participants were both reminded of their answer to the fairness question and told that aggregate reponses would be reported. In each treatment, the groups in the public good game were homogeneous in that all four members had been exposed to the same manipulation. At the end of the experiment, participants were paid privately based on the contribution decisions made in the public good game.

Our hypothesis parallels that for the dictator game. In this case, the recall and commitment mechanisms should promote dissonance which could be reduced by making larger contributions in the public good game.

Hypothesis 2 Participants in the recall, commitment, and combined treatments will make higher contributions than those in the baseline treatment. 


\section{Results}

The experiment was conducted in our university's experimental economics laboratory and programmed using the software developed by Fischbacher (2007). Participants were recruited from the undergraduate student body and 96 individuals participated in the experiment. No participant participated in more than one treatment, nor did any participant participate in our dictator game experiment (section 2). Participants received $\$ 5$ show-up fees in addition to their payoffs from the public good game.

Answers to the fairness question were identical across treatments with all participants agreeing with the statement about fairness. Figure 2 shows the number of participants in each treatment who chose contribution amounts $c_{i} \in\{2,5,8\}$. Contributions were similar in the baseline and recall treatments: In both cases, the modal contribution was 2 , followed by 5 and 8 . In contrast, in the commitment and combined treatments, we observe significantly higher contributions, with modal contributions of 5 , followed by 8 and 2 .

Figure 2: Contributions

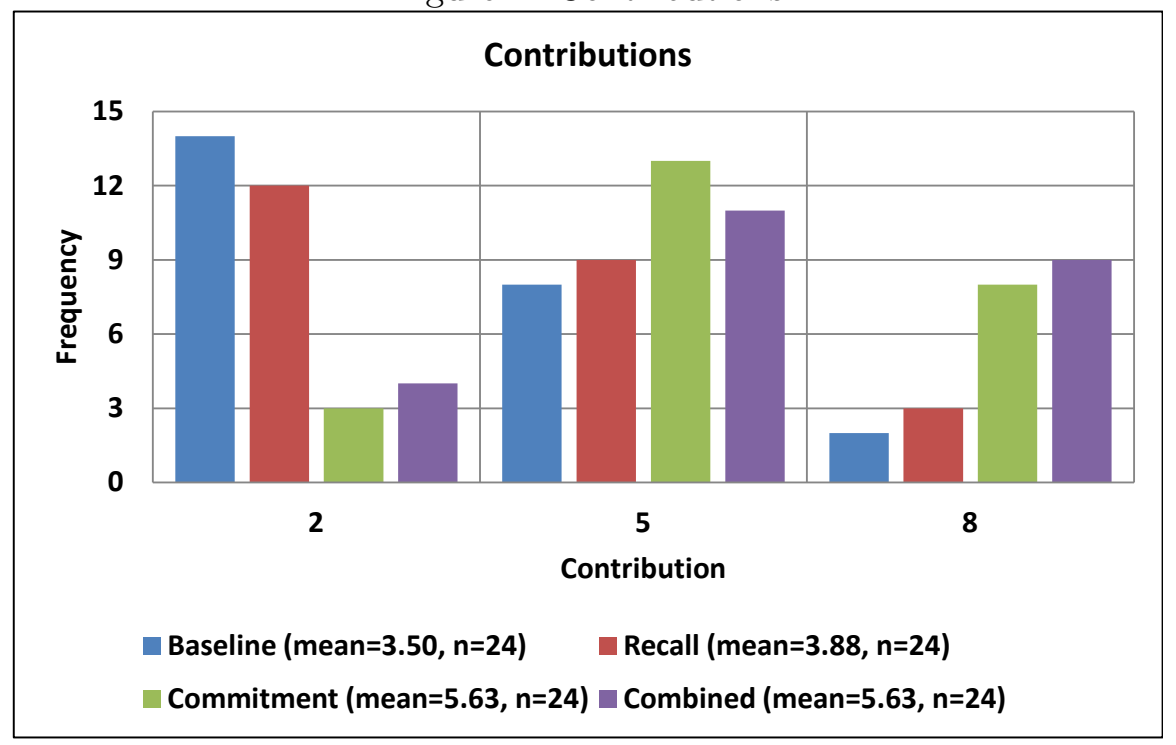

Table 2 presents the Wilcoxon $p$-values for all pairwise comparisons between treat- 
ments. As with the dictator game, all of the statistically significant differences are attributable to the commitment treatment variable. Specifically, with and without commitment, recall does not have a significant effect on contribution levels $(p=0.9548$ and $p=0.5326)$. In contrast, commitment has highly significant effects with and without recall $(p<0.01$ and $p<0.01)$, suggesting that the commitment treatment variable is the operand in promoting higher contributions.

Table 2: Wilcoxon $p$-values for comparisons between treatments

\begin{tabular}{lccc} 
& recall & commitment & combined \\
\hline baseline & 0.5326 & 0.0008 & 0.0014 \\
recall & - & 0.0057 & 0.0082 \\
commitment & - & - & 0.9548
\end{tabular}

\section{Discussion}

While we anticipated that the commitment mechanism would promote pro-social behaviour, we hypothesized that the same would be true for the recall mechanism, and this turned out not to be the case. The private nature of the recall mechanism, compared to the social aspect of the commitment mechanism, appears to be the key distinction between the two manipulations.

Regarding the recall mechanism, privately reminding participants of their statements about fairness could have been perceived as an obtrusive attempt by the experimenter to manipulate behaviour. If this was the case, then the lack of a significant effect is consistent with James and Gutkind (1985), who argue that the effects of external mechanisms are limited.

The interesting question is why commitment was so successful at promoting pro-social behaviour. Participants correctly anticipating that all participants would agree with the fairness statement would have recognized the inevitable discrepancy for other participants between receiving a comparatively low payoff and learning that fairness is important to all 
participants. Avoiding the guilt associated with creating such a situation by choosing prosocial actions is consistent with guilt aversion (Charness and Dufwenberg, 2006), which postulates that people avoid choosing options leaving others with payoffs falling short of expectations.

The dictator game provided a test of how the cognitive dissonance manipulations affected social preferences. The increased generosity of dictators in the commitment and combined treatments suggests that the commitment manipulation increased their concerns for the payoffs of recipients. With the public good game, different explanations are possible. The manipulations may have increased contributions directly by increasing concerns for the payoffs of others. Alternatively, knowing that all participants in each treatment had been exposed to the same manipulations, participants may have anticipated that others would contribute more, and then contributed more attempting to "match" the contributions of others. This explanation is consistent with previous research on conditional cooperation (Croson, Fatas and Neugebauer, 2005). Our experiment was not designed to disentangle the two explanations. However, the dictator game results suggest that the former explanation is relevant. The effect of increased concern regarding the payoffs of others might then have been magnified by conditional cooperation.

\section{Conclusion}

We present experiments on how cognitive dissonance can be used for promoting prosocial behaviour in dictator and public good games. In particular, we determine the effectiveness of using recall and commitment mechanisms for promoting dissonance which can be reduced by choosing pro-social actions. Recall, a private mechanism, had no significant effect on behaviour, whereas commitment, which involves a social aspect, had a large effect on the prevalence of pro-social behaviour. Consistent with modern theories

of cognitive dissonance, this is because the social aspect of reporting attitudes or beliefs 
creates stronger dissonance between one's self-image and behaviour, thereby providing a stronger motivation for (in our environment) pro-social behaviour.

Our findings contribute to the literature on how cognitive dissonance affects economic decision-making by showing that commitment mechanisms can be used for promoting equity and efficiency. An important path for future research is identifying other behaviours that can be influenced by promoting dissonance. For example, determining if commitment can be used for affecting risk and time preferences, both of which affect economic outcomes in a variety of circumstances.

\section{References}

Akerlof, G. A., Dickens, W., 1982. The economic consequences of cognitive dissonance. American Economic Review 72, 307-19.

Aronson, E., 1992. The return of the repressed: Dissonance theory makes a comeback. Psychological Inquiry 3, 301-11.

Aronson, E., 1994. The Social Animal, Seventh Edition. Freeman Press, San Francisco, CA.

Benabou, R., Tirole, J., 2011. Identity, morals, and taboos: Beliefs as assets. Quarterly Journal of Economics 126, 805-55.

Brandts, J., Charness, G., 2011. The strategy versus the direct-response method: A first survey of experimental comparisons. Experimental Economics 14, 375-98.

Charness, G., Dufwenberg, M., 2006. Promises and partnership. Econometrica 74, 15791601.

Croson, R., Fatas, E., Neugebauer, T., 2005. Reciprocity, matching and conditional cooperation in two public goods games. Economics Letters 87, 95-101.

Dickerson, C. A., Thibodeau, R., Aronson, E., Miller, D., 1992. Using cognitive dissonance to encourage water conservation. Journal of Applied Social Psychology 22, 841-54.

Dickinson, D. L., Oxoby, R. J., 2011. Cognitive dissonance, pessimism, and behavioral spillover effects. Journal of Economic Psychology 32, 295-306.

Falk, A., Zimmermann, F., 2011. Preferences for consistency. CESifo Working Paper No. 3528.

Festinger, L., 1957. A Theory of Cognitive Dissonance. Row and Peterson, Evanston, IL.

Fischbacher, U., 2007. z-Tree: Zurich toolbox for ready-made economic experiments. Experimental Economics 10, 171-78.

Harmon-Jones, E. and J. Mills, 1999. Cognitive Dissonance : Progress on a Pivotal Theory in Social Psychology. Washington D.C.: American Psychological Association. 
James, J., Gutkind, E., 1985. Attitude change revisited: Cognitive dissonance theory and development policy. World Development 13, 1139-49.

Konow, J., 2000. Fair shares: Accountability and cognitive dissonance in allocation decisions. American Economic Review 90, 1072-91.

Mazar, N., Amir, O., Ariely, D., 2008. The dishonesty of honest people: A theory of self-concept maintenance. Journal of Marketing Research 45, 633-44.

Montgomery, J., 1994. Revisiting Tally's Corner. Rationality and Society 6(4), 462-488.

Oxoby, R. J., 2003. Attitudes and allocations: Status, cognitive dissonance, and the manipulation of preferences. Journal of Economic Behavior and Organization 52, 365-85.

Oxoby, R. J., 2004. Cognitive dissonance, status, and growth of the underclass. The Economic Journal 114, 729-49.

Oxoby, R. J., McLeish, K. N., 2004. Specific decision and strategy vector methods in ultimatum bargaining: Evidence on the strength of other-regarding behavior. Economics Letters 84, 399-405.

Prendergast, C., Stole, L., 1996. Impetuous youngsters and jaded old-timers: Acquiring a reputation for learning. Journal of Political Economy 104, 1105-34.

Rabin, M., 1994. Cognitive dissonance and social change. Journal of Economic Behavior and Organization 32, 177-94. 